\title{
Effect of the $\delta$ Phase on the Tensile Properties of a Nickel-Based Superalloy
}

\author{
Qiang Zhu ${ }^{1}$, Gang Chen ${ }^{1}$, Chuanjie Wang ${ }^{1} \mathbb{(}$, Lukuan Cheng ${ }^{1}$, Heyong Qin ${ }^{2}$ and \\ Peng Zhang ${ }^{1, *}$ \\ 1 School of Materials Science and Engineering, Harbin Institute of Technology at Weihai, Weihai 264209, China; \\ zhuqiang@hit.edu.cn (Q.Z.); cg@hitwh.edu.cn (G.C.); cjwang@hitwh.edu.cn (C.W.); \\ 18766311751@163.com (L.C.) \\ 2 Institute of High Temperature Materials, Central Iron \& Steel Research Institute, Beijing 100081, China; \\ qinheyong@126.com \\ * Correspondence: pzhang@hit.edu.cn
}

Received: 1 October 2019; Accepted: 25 October 2019; Published: 27 October 2019

\begin{abstract}
Nickel-based superalloys are widely used in aerospace and other fields due to their excellent properties. In this study, the aging treatment and tensile tests of a GH4169 alloy were carried out. The effects of the $\delta$ phase on the alloy's mechanical properties and fracture behavior were studied. The results showed that the appearance of the $\delta$ phase changed from a short rod shape to a needle shape with an increase in aging time. The precipitation method changed from a single mode of precipitation along the grain boundary to two modes of precipitation along the grain boundary and direct precipitation inside the grain. The yield strength and ultimate tensile strength of the alloy first increased and then decreased with an increase in aging time and were related with the microstructure of the $\delta$ phase. The similar Widmanstatten structure was not conducive to the mechanical properties of the alloy. The distribution of the $\delta$ phase led to the generation of inhomogeneous strain and limited the surface roughening during plastic deformation. The voids initiated at the interface between the $\delta$ phase and the matrix $\gamma$ phase or directly from the $\delta$ phase fracture site.
\end{abstract}

Keywords: superalloy; microstructure evolution; tensile deformation; strain evolution; fracture

\section{Introduction}

Nickel-based superalloys are widely used in aerospace, nuclear engineering, energy, transportation, the petrochemical industry, etc., due to their perfect high temperature strength, oxidation resistance, thermal corrosion resistance, fatigue properties, and fracture toughness [1-5]. The mechanical properties of nickel-based superalloys are closely related to their microstructures. The $\delta$ phase in the GH4169 superalloy is an important precipitation phase. The morphology, distribution, and volume fraction of the $\delta$ phase can affect the grain structure and mechanical properties of the alloy. The morphology of the $\delta$ phase is mainly spherical, lamellar, and needle shaped or short rod shaped. The $\delta$ phase generally precipitates at the grain boundaries or the twin boundaries, resulting in a decrease in the plasticity of the alloy. Azadian et al. [6] pointed out that the $\delta$ phase increased the sensitivity of the thermal cracking of the alloy. However, the $\delta$ phase with an appropriate volume fraction can effectively limit grain growth during solution heat treatment. The presence of the $\delta$ phase at the grain boundaries also increases the resistance of the grain boundary creep rupture. Therefore, the presence of the $\delta$ phase with a proper volume fraction in the alloy can improve the impact toughness of the alloy [7].

Many studies about the mechanical properties of the GH4169 alloy have been conducted under different conditions, such as thermal compression, thermal tension, and room temperature tension [8-18]. Lin et al. [9] pointed out that the formation of the $\delta$ phase causes the accumulation of dislocations during 
hot tensile deformation, which leads to an increase in the work hardening rate of the alloy. The peak stress increased as the volume fraction of the $\delta$ phase increased. However, the alloy subjected to a rapid decrease in flow stress after reaching the peak stress, showed a significant softening phenomenon. He et al. [10] found that the generation of micro-cavities between the interfaces of the $\delta$ phase/matrix easily occurs with increased $\delta$ phases, and the high-temperature tensile properties are obviously deteriorated. Wen et al. [11] proposed that the dislocations pile up around the $\delta$ phase at a low strain, which would aggravate the strain hardening behavior and further lead to increased flow stress during hot deformation. Anderson et al. [12] found that the precipitation position of the $\delta$ phase has different effects on the mechanical properties of the GH4169 alloy. The $\delta$ phase tended to cause hardening of the alloy when it precipitated inside the grain, and the forming property of the alloy was improved when it precipitated at the grain boundary. Rao et al. [13] reported that the $\delta$ phase decreases yield and tensile strength but increases rupture ductility. Similar conclusions were drawn for creep and fatigue properties [14,15]. Zhang et al. [16] found that as the volume fraction of the $\delta$ phase increased, the yield strength and tensile strength of the GH4169 alloy decreased at room temperature, but the elongation increased. This result conflicts with most researchers who believe that the $\delta$ phase causes an increase in alloy brittleness. Valle et al. [17] proposed that the yield strength and ultimate tensile strength of the alloy did not increase significantly as the volume fraction of the $\delta$ phase changed. The ductility of the alloy decreased as the volume fraction of the $\delta$ phase increased. Chen et al. [18] found that the volume fraction of $\delta$ phase increased with the amount of rolling deformation, which increased the strength of the alloy. Although a large number of studies about the effects of the $\delta$ phase on mechanical properties have been carried out, no consistent conclusions have been reached.

The study of the $\delta$ phase in the GH4169 alloy occupies an important position. The service temperature of the $\mathrm{GH} 4169$ alloy is between $-253{ }^{\circ} \mathrm{C}$ and $650{ }^{\circ} \mathrm{C}$. Research on the tensile properties of the $\delta$ phase to GH4169 alloy at room temperature is still lacking. In the present study, the evolution behavior of the $\delta$ phase was studied. The influence of the volume fraction and morphology of the $\delta$ phase on mechanical properties at room temperature was studied. Moreover, coupling EBSD and laser confocal microscopy were first used to study the effects of the $\delta$ phase on strain evolution and surface roughening during plastic deformation.

\section{Materials and Methods}

The GH4169 alloy used in the present study was a cold rolled sheet with a thickness of $200 \mu \mathrm{m}$. Table 1 shows the chemical composition (mass fraction, \%) of the GH4169 alloy. The tensile specimens were machined to a $12 \mathrm{~mm}$ gauge length and a $5 \mathrm{~mm}$ gauge width (Figure 1 ). In order to reduce the impact of the specimen machining, the edges of the tensile specimens were polished with a 2000 grit $\mathrm{SiC}$ paper. To obtain the desirable microstructures, the tensile specimens were first solution treated at $1100{ }^{\circ} \mathrm{C}$ followed by water cooling (WC) and then aging treated at $900{ }^{\circ} \mathrm{C}$ for $1 \mathrm{~h}, 2 \mathrm{~h}, 4 \mathrm{~h}, 8 \mathrm{~h}, 16 \mathrm{~h}$, and $24 \mathrm{~h}$ followed by WC. The pole figures (PFs) of the aged specimens were characterized by EBSD with an accelerating voltage of $20 \mathrm{kV}$, a working distance (WD) of $15 \mathrm{~mm}$, a scanning step size of $0.5 \mu \mathrm{m}$, and a binning of $4 \times 4$. The crystallographic texture of an alloy is closely related to its chemical composition, microstructure, crystallography, as well as its processing conditions $[19,20]$. Figure 2 showed a set of (111), (001), and (011) PFs of the aged specimens at different aging times. It can be observed that the grain orientation in the aged specimens was random, and multiples of a random density (mrd) were relatively low. This indicates that the influence of the texture caused by sheet rolling was eliminated by heat treatment.

Table 1. Chemical composition (mass fraction, \%) of the GH4169 alloy.

\begin{tabular}{ccccccccc}
\hline $\mathbf{N i}$ & $\mathbf{C r}$ & $\mathbf{N b}$ & $\mathbf{M o}$ & $\mathrm{Al}$ & $\mathrm{Ti}$ & $\mathbf{C}$ & $\mathrm{Co}$ & $\mathrm{Fe}$ \\
\hline 52.80 & 18.73 & 5.24 & 3.02 & 0.52 & 0.95 & 0.03 & 0.03 & 18.68 \\
\hline
\end{tabular}




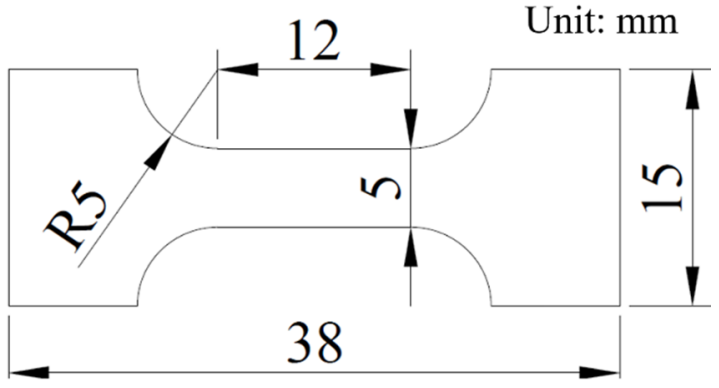

Figure 1. Schematic diagram of the tensile specimen.

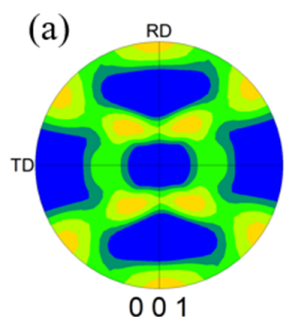

(b)

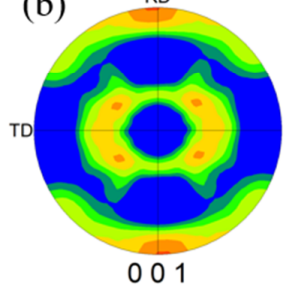

(c)

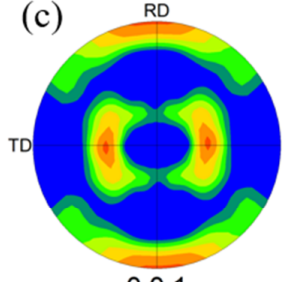

(d)

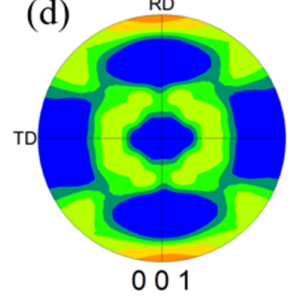

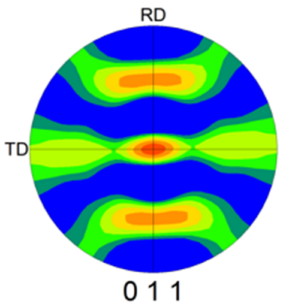
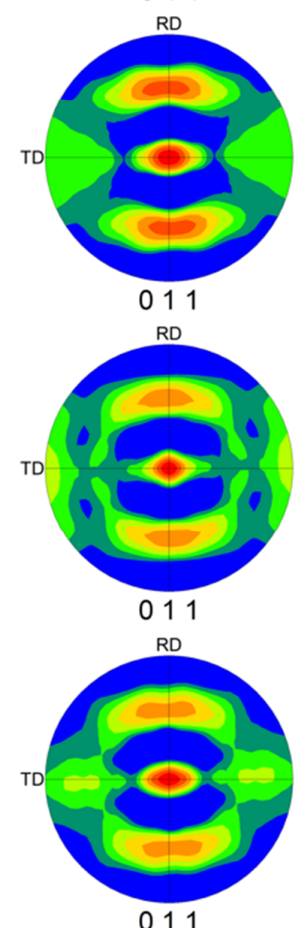

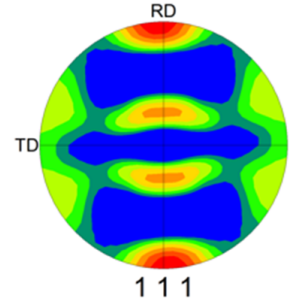

$\mathrm{RD}$

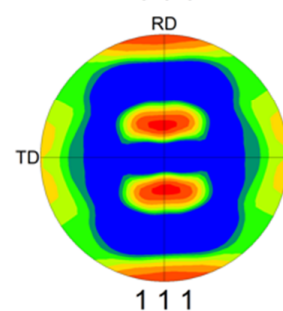

$\mathrm{RD}$

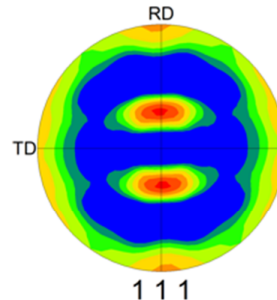

$\mathrm{RD}$

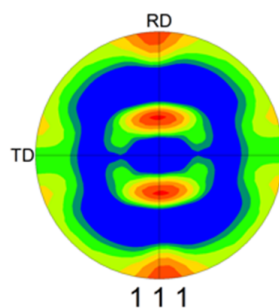

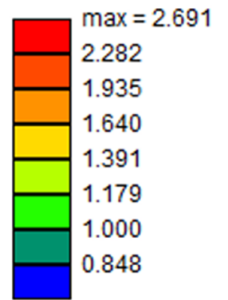

$\max =2.187$

$\square=\begin{aligned} & \max =2.1 \\ & 1.920 \\ & 1.685\end{aligned}$

1.685

1.479

1.298

1.139

1.000

0.878

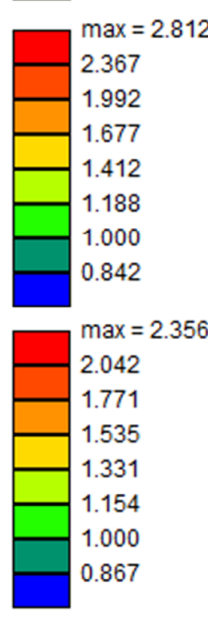

Figure 2. Pole figures of the aged specimens at different aging times. (a) $1 \mathrm{~h}$; (b) $4 \mathrm{~h}$; (c) $8 \mathrm{~h}$; (d) $16 \mathrm{~h}$.

Room temperature tensile tests with a constant strain rate of $0.01 \mathrm{~s}^{-1}$ were conducted on an Instron-5967 universal testing machine (Instron5967, INSTRON, Boston, MA, USA). Each set of tensile tests was performed four times to establish reproducibility.

In order to characterize the evolution of the $\delta$ phase by SEM (MERLIN Compact, Carl Zeiss AG, Heidenheim, Germany), the aged specimens and fractured specimens were prepared using mechanical grinding and polishing methods. Then, the specimens were etched chemically in a mixed solution with $5 \mathrm{~g} \mathrm{CuCl}_{2}+100 \mathrm{~mL} \mathrm{HCl}+100 \mathrm{~mL} \mathrm{C}_{2} \mathrm{H}_{5} \mathrm{OH}$. A confocal laser scanning microscope (CLSM, OLS3000, OLYMPUS, Tokyo, Japan) was used to detect the surface roughness of the deformed specimens with an area of $640 \mu \mathrm{m} \times 640 \mu \mathrm{m}$ and a scanning step size of $0.3 \mu \mathrm{m}$. The fracture morphologies of the specimens were characterized by SEM. 


\section{Results and Discussion}

\subsection{Evolution Behavior of $\delta$ Phase}

Figure 3 shows the microstructures of the $\delta$ phase at different aging times. It can be observed that the morphology and distribution of the $\delta$ phase changed significantly after aging treatment for different times. When the aging time was $2 \mathrm{~h}$, the $\delta$ phase exhibited a spherical shape and a short rod shape. The $\delta$ phase mainly precipitated along the grain boundary. When the aging time was $4 \mathrm{~h}$ and $8 \mathrm{~h}$, the needle-shaped $\delta$ phase precipitated at the grain boundaries, and the size of the needle-shaped $\delta$ phase increased significantly. When the $\delta$ phase precipitated at the grain boundaries, it was discontinuously distributed around the grain boundaries. Additionally, a small amount of the $\delta$ phase, which was formed by the transformation of the $\gamma^{\prime \prime}$ phase in the matrix $\gamma$ phase, was present inside the grains. The appearance of these $\delta$ phases was mostly a small spherical shape. When the aging time was $16 \mathrm{~h}$ and $24 \mathrm{~h}$, the precipitation of the needle-shaped $\delta$ phase extended along the grain boundary to inside the grain. The expansion direction of the precipitation of the needle-shaped $\delta$ phase was approximately parallel. Niang et al. [21] also reported this appearance of the $\delta$ phase. In addition, parts of the needle-shaped $\delta$ phases appeared to cross each other inside the grain, which is similar to a Widmanstatten structure. Similar experimental results have appeared in previous studies [12,22]. The reason for these phenomena is that the $\delta$ phase at the grain boundaries was combined with the $\delta$ phase, which was formed by the intragranular $\gamma^{\prime \prime}$ phase transition. Azadian et al. [6] pointed out that the precipitation of the $\gamma^{\prime \prime}$ phase occurred before $\delta$ phase precipitated in the GH4169 alloy, so there was a transition between the $\gamma^{\prime \prime}$ phase and the $\delta$ phase at an aging temperature of $900{ }^{\circ} \mathrm{C}$. Wei et al. [7] and Sundararaman et al. [23] also put forward such views.

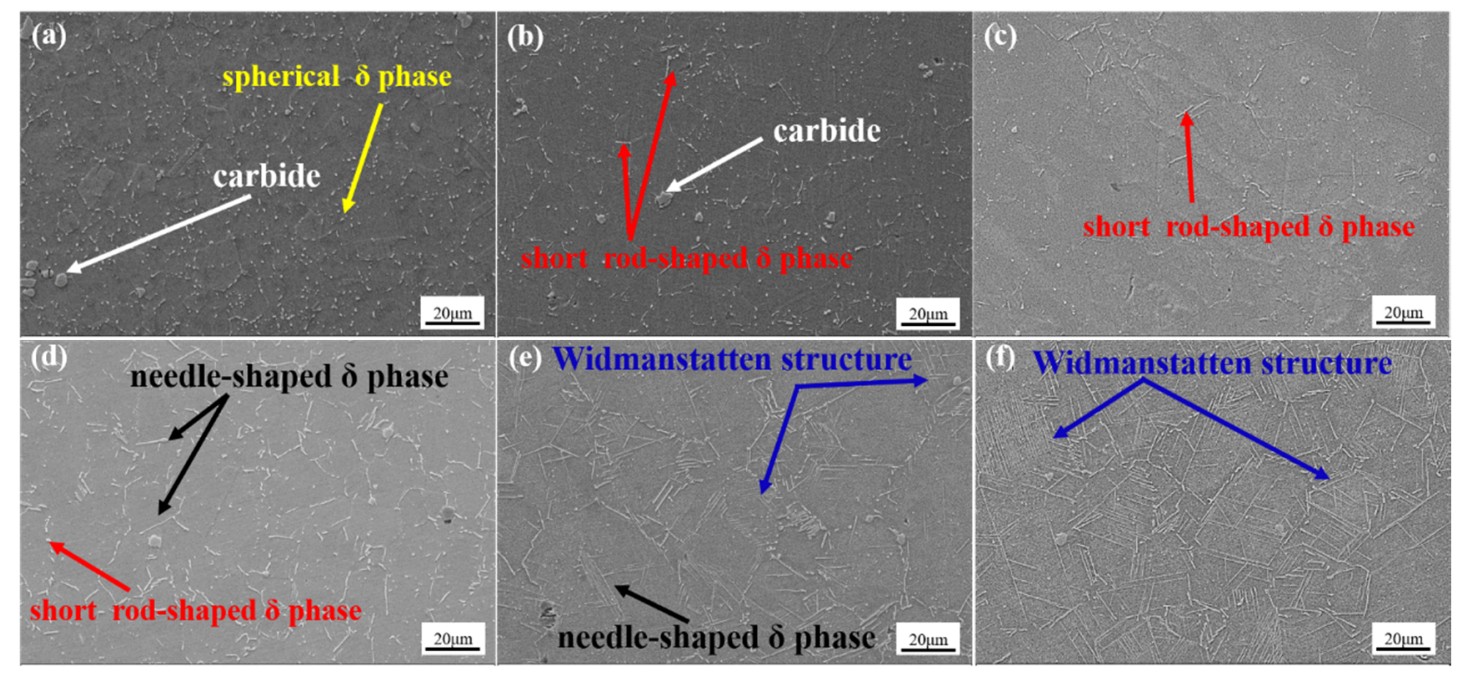

Figure 3. Microstructures of the $\delta$ phase at different aging times. (a) $1 \mathrm{~h} ;$ (b) $2 \mathrm{~h} ;$ (c) $4 \mathrm{~h}$; (d) $8 \mathrm{~h}$; (e) $16 \mathrm{~h}$; (f) $24 \mathrm{~h}$.

Figure 4 shows the volume fraction of the $\delta$ phase at different aging times. It can be seen that the volume fraction of the $\delta$ phase increased with an increase in aging time. As the aging time increased, the precipitation method changed from a single mode of precipitation along the grain boundary to two modes of precipitation along the grain boundary and direct precipitation inside the grain. The appearance of the $\delta$ phase changed from a short rod-shaped $\delta$ phase to a needle-shaped $\delta$ phase with an increase in aging time. The distortion strain energy between the $\delta$ phase and the matrix $\gamma$ phase was large due to non-coherent precipitation. In order to reduce the distortion strain energy, the needle-shaped $\delta$ phase extended inside the grain in a specific direction. 


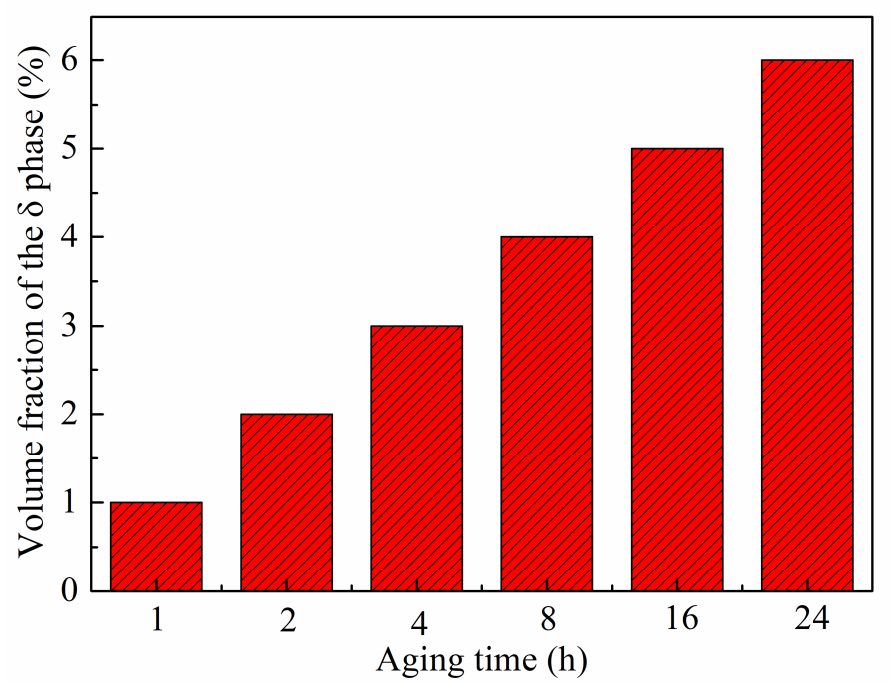

Figure 4. Volume fraction of the $\delta$ phase at different aging times.

\subsection{Mechanical Properties}

Figure 5a showed the engineering stress-engineering strain curves of GH4169 alloy. It can be seen that the elastic strain of the alloy was small, and the yield of the alloy was reached at a small strain. The flow stress of the alloy showed a clear upward trend with an increase in plastic strain, which was due to work hardening during plastic deformation. Figure $5 \mathrm{~b}$ shows an enlarged view of the red framed portion in Figure 5a. For a given engineering strain, as the aging time increased from $1 \mathrm{~h}$ to $24 \mathrm{~h}$, the flow stress of the alloy first increased, and then the flow stress decreased, which is related to the volume fraction and morphology of the $\delta$ phase (Figure $5 \mathrm{c}$ ).
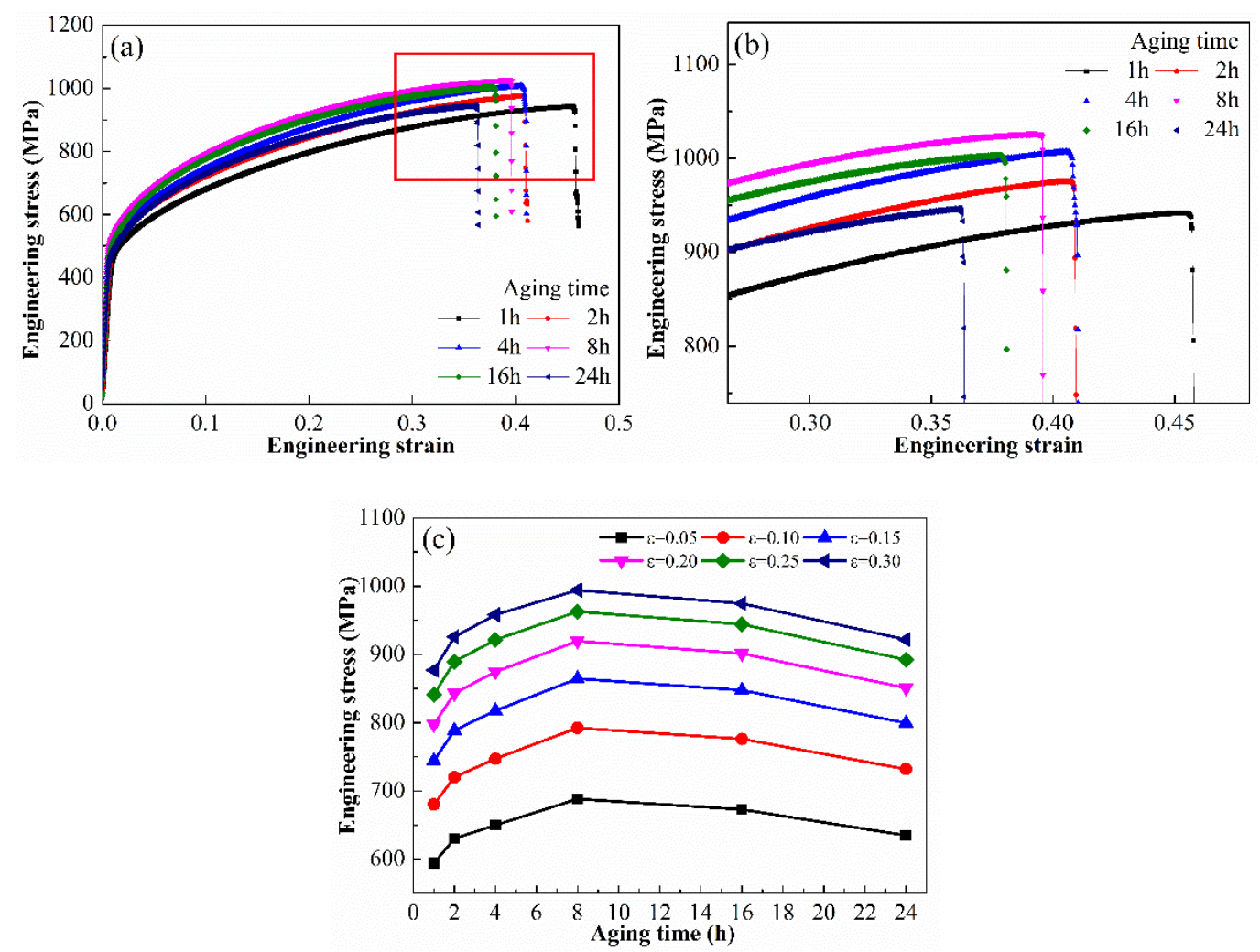

Figure 5. (a) Engineering stress-engineering strain curves of the GH4169 alloy; (b) enlarged view of the red framed portion in Figure 5a; (c) engineering stress versus aging time. 
Figure 6a shows the change of yield strength $\left(\sigma_{s}\right)$ and ultimate tensile strength $\left(\sigma_{b}\right)$ of the alloy with various aging times. The trends of the changes in $\sigma_{s}$ and $\sigma_{b}$ were consistent with those in the flow stress-that is, the $\sigma_{s}$ and $\sigma_{b}$ of the alloy increased first and then decreased with an increase in the aging time. Compared with the $\sigma_{s}$, the $\sigma_{b}$ changed more significantly. This indicates that the influence of the $\delta$ phase on the $\sigma_{b}$ at room temperature was more distinct. The $\sigma_{s}$ and $\sigma_{b}$ of the sample with the aging time of $8 \mathrm{~h}$ reached maximum values, which were approximately $513 \mathrm{MPa}$ and $1043 \mathrm{MPa}$, respectively. The fracture elongation $\left(\varepsilon_{f}\right)$ in Figure $6 \mathrm{~b}$ gradually decreased as the aging time increased. The $\varepsilon_{f}$ of the specimen with the aging time of $24 \mathrm{~h}$ reached its minimum value, which was approximately 0.371 .
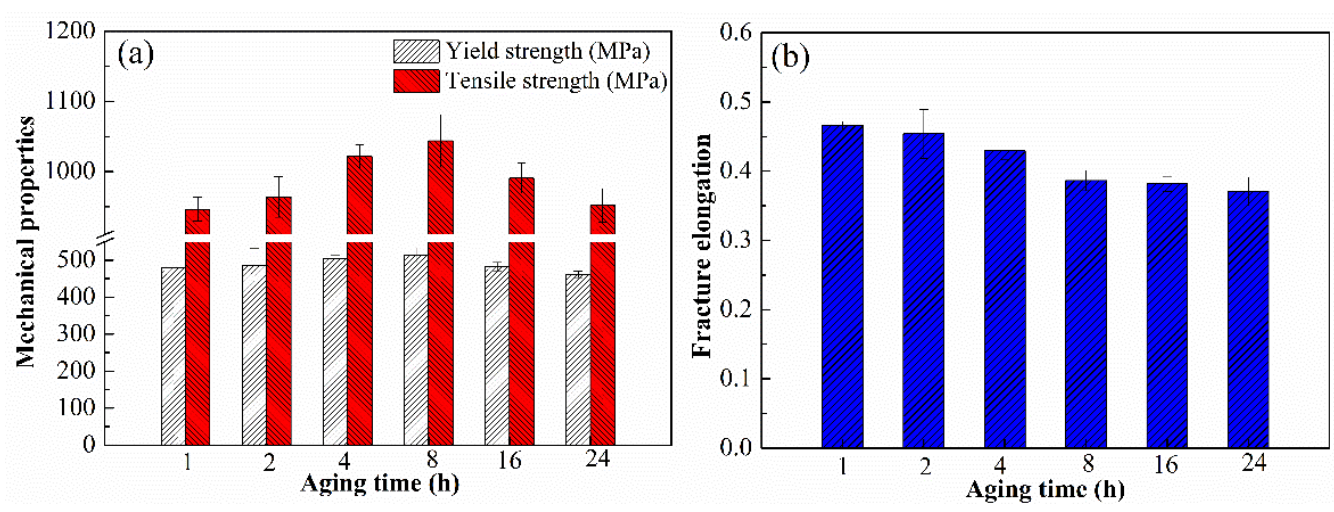

Figure 6. Mechanical properties of the GH4169 alloy with various aging times. (a) Yield strength and ultimate tensile strength; (b) fracture elongation.

When the aging time was less than $8 \mathrm{~h}$, the $\delta$ phase mainly precipitated along the grain boundary, and the volume fraction of the $\delta$ phase increased with the aging time. The dislocations accumulated near the $\delta$ phase, and the pinning effect of the $\delta$ phase was further strengthened due to precipitation strengthening. The $\sigma_{s}$ and $\sigma_{b}$ of the alloy continued to increase. At an aging time of $8 \mathrm{~h}$, the $\sigma_{s}$ and $\sigma_{b}$ of the alloy reached their maximum values. This is basically consistent with the results obtained by reference [24] after an aging treatment of 5-10 h. For the aging treatment of $16 \mathrm{~h}$ and $24 \mathrm{~h}$, the microstructure of the $\delta$ phase was similar to the Widmanstatten structure. Lei et al. [25] proposed that the Widmanstatten structure would reduce the $\sigma_{s}, \sigma_{b}$, and $\varepsilon_{f}$ of the alloy. Gil et al. [26] pointed out that the Widmanstatten structure reduced the $\varepsilon_{f}$ of the alloy. Therefore, the $\sigma_{s}$ and $\sigma_{b}$ of the alloy decreased when the aging treatment time was more than $16 \mathrm{~h}$. Additionally, the precipitation of the $\delta$ phase in the matrix $\gamma$ phase belonged to the non-coherent transition during the aging treatment process. The precipitation position of the $\delta$ phase induced a notable stress concentration. The dislocation accumulation during the plastic deformation process led to an increase in the strength of the alloy. However, the local stress concentration was also more profound. Therefore, the plasticity of the alloy was lowered, causing the $\varepsilon_{f}$ of the alloy to continuously decrease.

\subsection{Strain Evolution}

Local misorientation could be used to reveal the strain evolution during plastic deformation in the deformed materials [27]. Figure 7 shows the Kernel average misorientation (KAM) of the specimen surface for the aged specimens and fractured specimens at different aging times. KAM is a local misorientation defined as an average misorientation of a point with all of its neighbours in a grain. The KAM analysis uses the maximum misorientation of 5 degrees and 0-point kernels to maximum misorientation. It could be observed that the KAM values (mainly between $0^{\circ}$ and $0.5^{\circ}$ ) were very low and evenly distributed at the grain boundaries and inside the grains for the aged specimens. However, the KAM values (mainly between $0.5^{\circ}$ and $2^{\circ}$ ) were very high and not evenly distributed for the fractured specimens. The average KAM values were higher at the grain boundaries than those inside the grains for the fractured specimens. This phenomenon was related to the distribution of the $\delta$ phase. 
This phenomenon indicates that an obvious plastic strain was produced in the grains after tensile deformation and that the plastic strain was mainly concentrated at the grain boundaries. Additionally, it the average KAM value could be seen to obviously increase with aging time. This indicates that the presence of the $\delta$ phase led to an increase in the average KAM value.

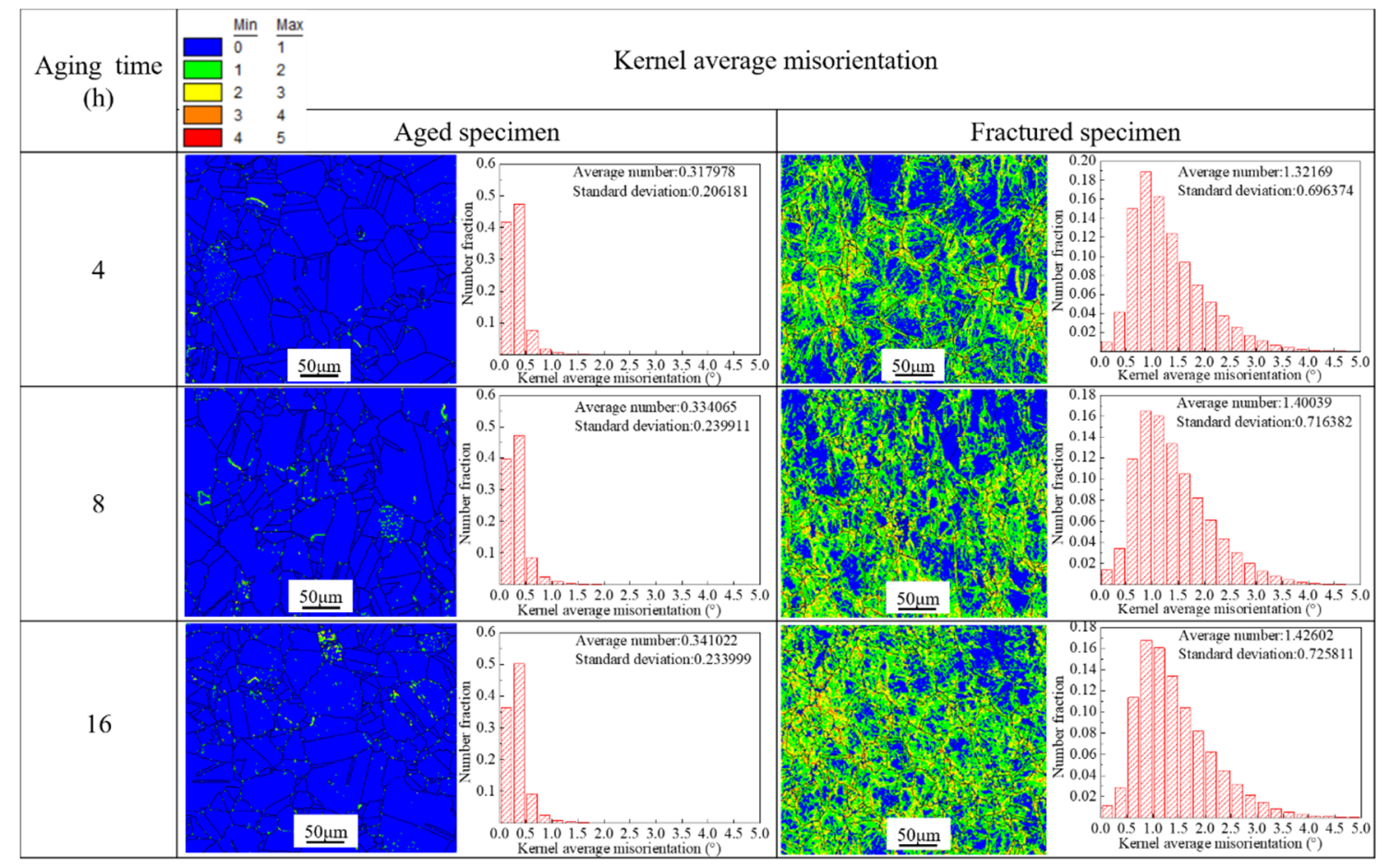

Figure 7. KAM of the alloy measured for the aged specimens and fractured specimens at different aging times.

During the plastic deformation process, the roughness of the specimen's surface changed significantly, which was closely related to the crystallographic orientation [28]. The crystallographic orientation with regard to the applied stress controlled the plastic strain, which was produced inside each grain [29]. The crystallographic orientation could be characterized by the Schmid factor. Grains with a low Schmid factor were deformed with difficulty, while the greater number of hindrances and grains with a high Schmid factor were easily deformed due to fewer hindrances. Figure 8 displays the Schmid factor maps of aged specimens and fractured specimens at different aging times. It can be observed that the Schmid factor values of each grain in the aged specimens were different (Figure 8a,c,e). Compared with the aged specimens, the Schmid factor values of the fractured specimens decreased (Figure $8 \mathrm{~b}, \mathrm{~d}, \mathrm{f}$ ). This indicates that the Schmid factor values of the grains gradually decreased during plastic deformation, and the deformation of the grains became more and more difficult. 

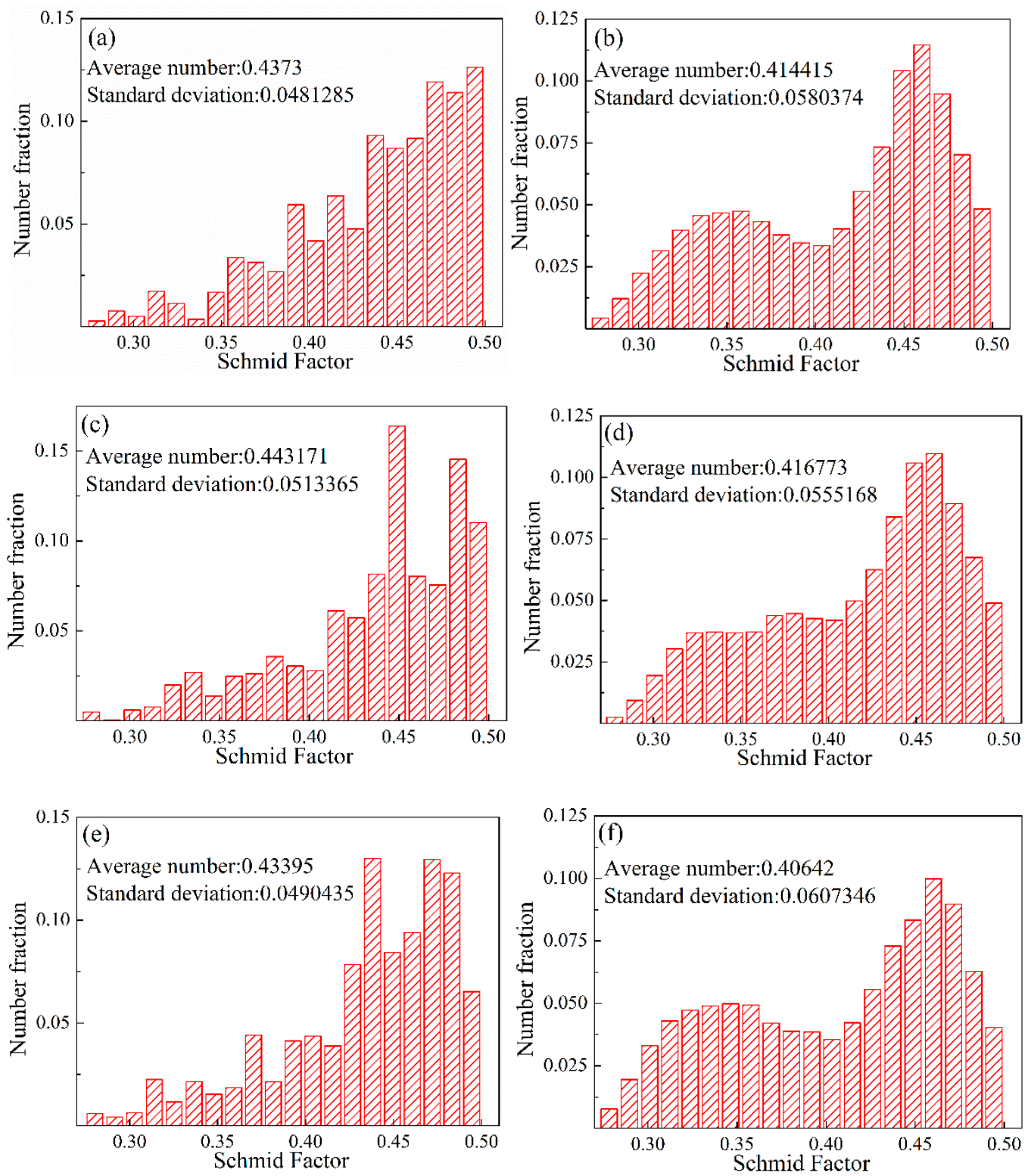

Figure 8. Schmid factor maps of the alloy at different aging times. (a) Aged specimens with an aging time of $4 \mathrm{~h}$; (b) fractured specimens with an aging time of $4 \mathrm{~h}$; (c) aged specimens with an aging time of $8 \mathrm{~h}$; (d) fractured specimens with an aging time of $8 \mathrm{~h}$; (e) aged specimens with an aging time of $16 \mathrm{~h}$; (f) fractured specimens with an aging time of $16 \mathrm{~h}$.

Grains with a low Schmid factor induced local ridge, and grains with a high Schmid factor resulted in a local depression on the specimen surface during tensile deformation. Therefore, the surface roughening phenomena were attributed to the difference in the Schmid factor of the adjacent grains [30]. The surface roughness of the deformed specimens with various aging times is displayed in Figure 9. The surface roughness of the deformed specimens under a strain of 0.2 significantly decreased with an increase in aging time. This is because the grains in the surface layer were more obstructed due to the presence of the $\delta$ phase. This indicates that the $\delta$ phase is conducive to reducing the coarsening of the surface layer grains. 


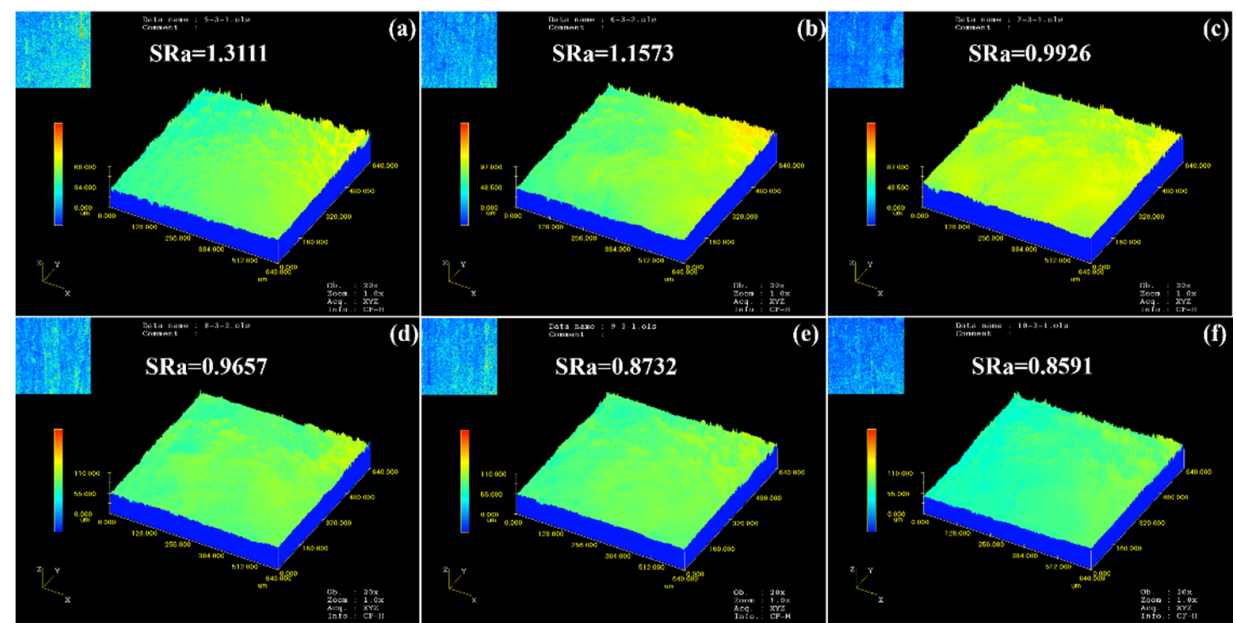

Figure 9. Surface roughness of the deformed specimens with various aging times under the condition of a strain of 0.2. (a) $1 \mathrm{~h}$; (b) $2 \mathrm{~h}$; (c) $4 \mathrm{~h}$; (d) $8 \mathrm{~h}$; (e) $16 \mathrm{~h}$; (f) $24 \mathrm{~h}$.

\subsection{Fracture Morphology and Fracture Mechanism}

Figure 10 shows the morphology of the $\delta$ phase near the fracture after tensile deformation at different aging times. The needle-shaped $\delta$ phase broke, and some voids of different sizes appeared at the fracture position of the $\delta$ phase. Additionally, the voids were also formed when the interfaces of the matrix $\gamma$ phase and the carbide phase were separated, or the carbides were broken [9]. Figure 11 shows the fracture morphology of the alloy at different aging times. Equiaxed dimples were clearly visible at the fracture. These dimples were formed by the aggregation of micropores during the plastic deformation. As the micropores expanded, the alloy finally broke. With an increase in aging time, the number and size of the dimples gradually decreased, indicating that the plasticity of the alloy gradually decreased with an increase of aging time. There were also some elongated deep voids in Figure 11, probably due to the crack expanding along the $\delta$ phase, and the $\delta$ phase was peeled off from the alloy at the time of the fracture.
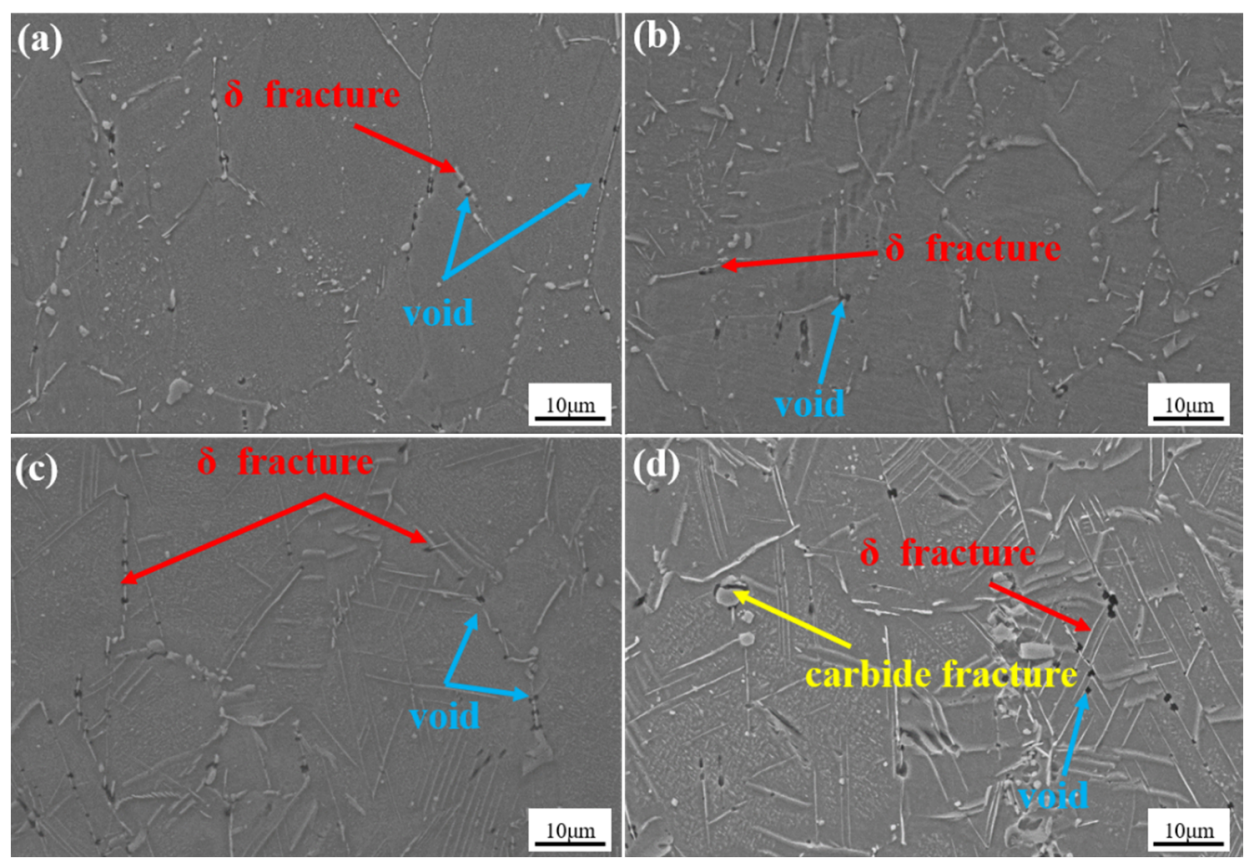

Figure 10. Morphology of the $\delta$ phase near the fracture after tensile deformation at different aging times. (a) 4h; (b) 8h; (c) 16h; (d) $24 \mathrm{~h}$. 

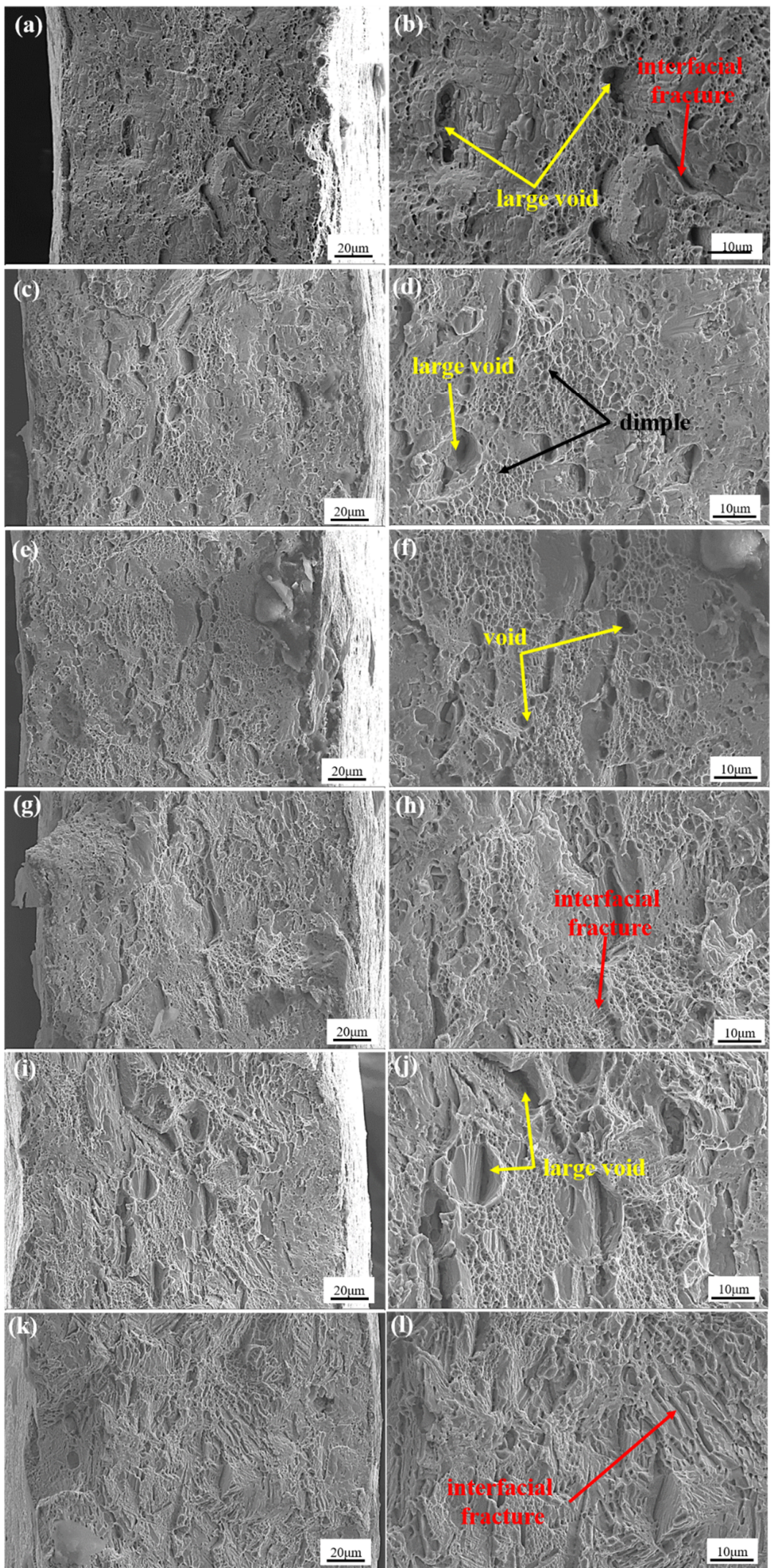

Figure 11. Fracture morphology of the alloy at different aging times. (a,b) 1 h; (c,d) 2 h; (e,f) 4 h; $(\mathbf{g}, \mathbf{h}) 8 \mathrm{~h} ;(\mathbf{i}, \mathbf{j}) 16 \mathrm{~h} ;(\mathbf{k}, \mathbf{l}) 24 \mathrm{~h}$. 
The matrix $\gamma$ phase contained non-metallic inclusions, precipitates, or brittle phases. The mechanical properties of these materials were very different from those of the matrix $\gamma$ phase. When plastic deformation occurred, the slip would preferentially start along the slip surface of the matrix $\gamma$ phase. However, these materials with different phase components in the matrix $\gamma$ phase hindered the motion of the dislocations, resulting in the accumulation of dislocations in the vicinity of the non-matrix phase and resulting in local stress concentration. The voids formed in the vicinity of the $\delta$ phase in Figure 10 were caused by the stress concentration due to dislocation accumulation during plastic deformation. As the plastic deformation of the alloy continued, the stress value at the $\delta$ phase was greater than its own strength or exceeded the interface strength between the matrix $\gamma$ phase and the $\delta$ phase, which caused a void to form in the matrix $\gamma$ phase, and the position of the $\delta$ phase usually became a void initiation position. The presence of the $\delta$ phase causes a large number of voids to nucleate near the $\delta$ phase, thereby promoting the formation of voids during tensile deformation. Therefore, as the volume fraction of the $\delta$ phase increases, the $\varepsilon_{f}$ of the material gradually decreases.

\section{Conclusions}

The microstructure evolution of the GH4169 alloy was analyzed via SEM, EBSD, and CLSM in this study. The tensile deformation of the GH4169 alloy with various volume fractions of the $\delta$ phase was carried out. The main conclusions are as follows:

(1) As the aging time increased, the short rod-shaped $\delta$ phases evolved into needle-shaped $\delta$ phases. The $\delta$ phase precipitated not only along the grain boundary but also directly inside the grain. The volume fraction of the $\delta$ phase increased with an increase of aging time.

(2) The $\sigma_{s}$ and $\sigma_{b}$ of the alloy first increased and then decreased with an increase in aging time. The $\sigma_{s}$ and $\sigma_{b}$ of the alloy reached their maximum values at an aging time of $8 \mathrm{~h}$. The $\varepsilon_{f}$ gradually decreased as the aging time increased. The similar Widmanstatten structure was not conducive to the mechanical properties of the alloy.

(3) The average KAM values were higher at the grain boundaries than those inside the grains for the fractured specimens, which were related to the distribution of the $\delta$ phase. The surface roughness of the deformed specimens significantly decreased with an increase of aging time. This indicates that the $\delta$ phase was conducive to reducing the coarsening of the surface layer grains.

(4) The needle-shaped $\delta$ phase broke and some distinct micropores of different sizes appeared at the fracture position of the $\delta$ phase. When the stress value at the $\delta$ phase was greater than its own strength or exceeded the interface strength between the matrix $\gamma$ phase and the $\delta$ phase, voids formed in the matrix $\gamma$ phase, and the position of the $\delta$ phase usually became a void initiation position.

Author Contributions: Conceptualization, P.Z.; data curation, Q.Z. and G.C.; formal analysis, C.W., L.C., and H.Q.; investigation, Q.Z. and C.W.; methodology, Q.Z.; resources, H.Q. and P.Z.; software, Q.Z., G.C., and L.C.; visualization, G.C.; writing—original draft, Q.Z.; writing—review and editing, P.Z.

Funding: This research was funded by the Training Program of the Major Research Plan of the National Natural Science Foundation of China (Grant No. 91860129), the National Natural Science Foundation of China (Grant No. 51575129), and the key research and development program of Shandong Province (Grant No. 2016GGX102026).

Conflicts of Interest: The authors declare no conflict of interest.

\section{References}

1. Texier, D.; Stinville, J.C.; Echlin, M.P.; Pierret, S.; Villechaise, P.; Pollock, T.M.; Cormier, J. Short crack propagation from cracked non-metallic inclusions in a Ni-based polycrystalline superalloy. Acta Mater. 2019, 165, 241-258. [CrossRef]

2. Jeong, G.U.; Jin, C.K.; Seo, H.Y.; Kang, C.G. Experimental Investigation on the Deformation Behavior of Inconel 625 Superalloy at High Temperatures. Metals 2019, 9, 720. [CrossRef]

3. Zhang, P.; Hu, C.; Ding, C.G.; Zhu, Q.; Qin, H.Y. Plastic deformation behavior and processing maps of a Ni-based superalloy. Mater. Des. 2015, 65, 575-584. [CrossRef] 
4. He, D.G.; Lin, Y.C.; Tang, Y.; Li, L.; Chen, J.; Chen, M.S.; Chen, X.M. Influences of solution cooling on microstructures, mechanical properties and hot corrosion resistance of a nickel-based superalloy. Mater. Sci. Eng. A 2019, 746, 372-383. [CrossRef]

5. Zhong, L.; Hu, H.; Liang, Y.; Huang, C. High Cycle Fatigue Performance of Inconel 718 Alloys with Different Strengths at Room Temperature. Metals 2019, 9, 13. [CrossRef]

6. Azadian, S.; Wei, L.Y.; Warren, R. Delta phase precipitation in Inconel 718. Mater. Charact. 2004, 53, 7-16. [CrossRef]

7. Wei, X.P.; Zheng, W.J.; Song, Z.G.; Lei, T.; Yong, Q.L.; Xie, Q.C. Strain-induced precipitation behavior of $\delta$ phase in Inconel 718 alloy. J. Iron Steel Res. Int. 2014, 21, 375-381. [CrossRef]

8. DuPont, J.N.; Lippold, J.C.; Kiser, S.D. Welding metallurgy and weldability of nickel base alloys; John Wiley \& Sons, Inc.: Hoboken, NJ, USA, 2009.

9. Lin, Y.C.; Deng, J.; Jiang, Y.Q.; Wen, D.X.; Liu, G. Effects of initial $\delta$ phase on hot tensile deformation behaviors and fracture characteristics of a typical Ni-based superalloy. Mater. Sci. Eng. A 2014, 598, 251-262. [CrossRef]

10. He, D.G.; Lin, Y.C.; Wang, L.H.; Wu, Q.; Zu, Z.H.; Cheng, H. Influences of pre-precipitated $\delta$ phase on microstructures and hot compressive deformation features of a nickel-based superalloy. Vacuum 2019, 161, 242-250. [CrossRef]

11. Wen, D.X.; Lin, Y.C.; Li, X.H.; Singh, S.K. Hot deformation characteristics and dislocation substructure evolution of a nickel-base alloy considering effects of $\delta$ phase. J. Alloy. Compd. 2018, 764, 1008-1020. [CrossRef]

12. Anderson, M.; Thielin, A.L.; Bridier, F.; Bocher, P.; Savoie, J. $\delta$ Phase precipitation in Inconel 718 and associated mechanical properties. Mater. Sci. Eng. A 2017, 679, 48-55. [CrossRef]

13. Rao, G.A.; Kumar, M.; Srinivas, M.; Sarma, D.S. Effect of standard heat treatment on the microstructure and mechanical properties of hot isostatically pressed superalloy inconel 718. Mater. Sci. Eng. A 2003, 355, 114-125. [CrossRef]

14. Huang, Y.; Langdon, T.G. The evolution of delta-phase in a superplastic Inconel 718 alloy. J. Mater. Sci. 2007, 42, 421-427. [CrossRef]

15. Kuo, C.M.; Yang, Y.T.; Bor, H.Y.; Wei, C.N.; Tai, C.C. Aging effects on the microstructure and creep behavior of Inconel 718 superalloy. Mater. Sci. Eng. A 2009, 510, 289-294. [CrossRef]

16. Zhang, X.C.; Li, H.C.; Zeng, X.; Tu, S.T.; Zhang, C.C.; Wang, Q.Q. Fatigue behavior and bilinear Coffin-Manson plots of Ni-based GH4169 alloy with different volume fractions of $\delta$ phase. Mater. Sci. Eng. A 2017, 682, 12-22. [CrossRef]

17. Valle, L.C.M.; Araújo, L.S.; Gabriel, S.B.; Dille, J.; De Almeida, L.H. The effect of $\delta$ phase on the mechanical properties of an Inconel 718 superalloy. J. Mater. Eng. Perform. 2013, 22, 1512-1518. [CrossRef]

18. Chen, Y.T.; Yeh, A.C.; Li, M.Y.; Kuo, S.M. Effects of processing routes on room temperature tensile strength and elongation for Inconel 718. Mater. Des. 2017, 119, 235-243. [CrossRef]

19. Jayaganthan, R.; Brokmeier, H.G.; Schwebke, B.; Panigrahi, S.K. Microstructure and texture evolution in cryorolled Al 7075 alloy. J. Alloy. Compd. 2010, 496, 183-188. [CrossRef]

20. Pedersen, K.O.; Lademo, O.G.; Berstad, T.; Furu, T.; Hopperstad, O.S. Influence of texture and grain structure on strain localisation and formability for AlMgSi alloys. J. Mater. Process. Tech. 2008, 200, 77-93. [CrossRef]

21. Niang, A.; Viguier, B.; Lacaze, J. Some features of anisothermal solid-state transformations in alloy 718. Mater. Charact. 2010, 61, 525-534. [CrossRef]

22. Lin, Y.C.; He, D.G.; Chen, M.S.; Chen, X.M.; Zhao, C.Y.; Ma, X. Study of flow softening mechanisms of a nickel-based superalloy with $\delta$ phase. Arch. Metall. Mater. 2016, 61, 1537-1546. [CrossRef]

23. Sundararaman, M.; Mukhopadhyay, P.; Banerjee, S. Precipitation and room temperature deformation behaviour of Inconel 718. Superalloys 1994, 718, 419-440.

24. Ye, N.Y.; Cheng, M.; Zhang, S.H.; Song, H.W.; Zhou, H.W.; Wang, P.B. Effect of $\delta$ phase on mechanical properties of GH4169 alloy at room temperature. J. Iron Steel Res. Int. 2015, 22, 752-756. [CrossRef]

25. Lei, Z.N.; Gao, P.F.; Li, H.W.; Cai, Y.; Li, Y.X.; Zhan, M. Comparative analyses of the tensile and damage tolerance properties of tri-modal microstructure to widmanstätten and bimodal microstructures of TA15 titanium alloy. J. Alloy. Compd. 2019, 788, 831-841. [CrossRef]

26. Gil, F.J.; Ginebra, M.P.; Manero, J.M.; Planell, J.A. Formation of $\alpha$-Widmanstätten structure: Effects of grain size and cooling rate on the Widmanstätten morphologies and on the mechanical properties in Ti6Al4V alloy. J. Alloy. Compd. 2001, 329, 142-152. [CrossRef] 
27. Wright, S.I.; Nowell, M.M.; Field, D.P. A review of strain analysis using electron backscatter diffraction. Microsc. Microanal. 2011, 17, 316-329. [CrossRef]

28. Meng, B.; Fu, M.W. Size effect on deformation behavior and ductile fracture in microforming of pure copper sheets considering free surface roughening. Mater. Des. 2015, 83, 400-412. [CrossRef]

29. Jorge-Badiola, D.; Iza-Mendia, A.; Gutierrez, I. Study by EBSD of the development of the substructure in a hot deformed 304 stainless steel. Mater. Sci. Eng. A 2005, 394, 445-454. [CrossRef]

30. Wouters, O.; Vellinga, W.P.; Van Tijum, R.; De Hosson, J.T.M. Effects of crystal structure and grain orientation on the roughness of deformed polycrystalline metals. Acta Mater. 2006, 54, 2813-2821. [CrossRef]

(C) 2019 by the authors. Licensee MDPI, Basel, Switzerland. This article is an open access article distributed under the terms and conditions of the Creative Commons Attribution (CC BY) license (http://creativecommons.org/licenses/by/4.0/). 